\title{
Pertumbuhan dan Produksi Kedelai Hitam dengan Pemberian Jenis Biomassa dan Dosis Pemupukan Kalsium pada Budidaya Jenuh Air di Lahan Pasang Surut
}

\author{
Growth and Production of Black Soybean on Giving of Biomass and Dose of Ca Fertilizing with \\ Saturated Soil Culture on Tidal Swamp
}

\author{
Muhammad Syamil Hizbi dan Munif Ghulamahdi*
}

Departemen Agronomi dan Hortikultura, Fakultas Pertanian, Institut Pertanian Bogor

(Bogor Agricultural University), Jl. Meranti, Kampus IPB Darmaga, Bogor 16680, Indonesia

Telp. \& Faks.62-251-8629353 e-mail agrohort@apps.ipb.ac.id

*Penulis Korespondensi : mghulamahdi@yahoo.com

Disetujui : 26 September 2018 / Published Online 06 Mei 2019

\begin{abstract}
Utilizing of Saturated Soil Culture on tidal swamps land is one solution to improve national production of soybean. Biomass giving and calcium fertilizing are considered to complete the packet of saturated soil culture technology. The objective of this study was to determine source of biomass and dose of Ca fertilizing which increase growth and production black soybean with saturated soil culture on tidal swamp. The research was conducted in Karyabhakti Village, Rantau Rasau, Tanjung Jabung Timur, Jambi from August to November 2017. Nested design was used for this research with two factor i.e. source of biomass and dose of Ca fertilizing. Source of biomass had three level, control, Cyperus biomass, and rice straw, while dose of Ca fertilizing had four level that is control, $250 \mathrm{~kg} \mathrm{ha}^{-1}, 500 \mathrm{~kg} \mathrm{ha}^{-1}$, and $750 \mathrm{~kg} \mathrm{ha}^{-1}$. Combinations of two factor were replicated by three replication so there were 36 research units. The results showed that singular factor effect of biomass source and dose of Ca fertilizing had given significant effect to improve plant height, number of leaves, dry weight of root nodule, weight of 100 seeds, tile weight, and plant productivity of black soybean. Cyperus biomass gave the best response to increase productivity black soybean i.e. 2.74 ton ha ${ }^{-1}$, while the dose of 500 $\mathrm{kg} / \mathrm{ha}$ Ca fertilizing was the best productivity i.e. 2.49 ton $\mathrm{ha}^{-1}$. Interaction of both factors just effect significantly for high of plant, stem dried weight, and sum of filled up pods.
\end{abstract}

Keywords: biomass, black soybean, Ca fertilizing, saturated soil culture, tidal swamp land

\section{ABSTRAK}

Penggunaan Budidaya Jenuh Air (BJA) pada lahan pasang surut merupakan salah satu solusi peningkatan produksi kedelai nasional. Pemberian biomassa dan pemupukan Ca menjadi pertimbangan dalam melengkapi paket teknologi budidaya jenuh air. Penelitian ini bertujuan untuk menentukan jenis biomassa dan dosis pemupukan Ca yang secara nyata meningkatkan pertumbuhan dan produksi kedelai hitam dengan budidaya jenuh air di lahan pasang surut. Penelitian dilakukan di Desa Karyabhakti, Kecamatan Rantau Rasau, Kabupaten Tanjung Jabung Timur, Jambi pada Agustus hingga November 2017. Rancangan petak tersarang digunakan pada penelitian ini dengan dua faktor, yaitu sumber biomassa dan dosis pemupukan $\mathrm{Ca}$. Sumber biomassa terdiri atas tiga level antara lain kontrol, biomassa teki-tekian, dan jerami, sedangkan dosis pemupukan Ca terdiri atas empat level, yaitu kontrol, $250 \mathrm{~kg} \mathrm{ha}^{-1}, 500 \mathrm{~kg} \mathrm{ha}^{-1}$, dan $750 \mathrm{~kg} \mathrm{ha}^{-1}$. Kombinasi keduanya diulang sebanyak tiga ulangan sehingga menghasilkan 36 satuan percobaan. Hasil penelitian menunjukkan bahwa pengaruh faktor tunggal sumber biomassa dan dosis pemupukan $\mathrm{Ca}$ secara umum berbeda sangat nyata dalam meningkatkan tinggi tanaman, jumlah daun, bobot kering bintil akar, bobot 100 biji, bobot ubinan, dan produktivitas kedelai hitam. Produktivitas tertinggi pengaruh faktor tunggal sumber biomassa adalah perlakuan pemberian biomassa teki sebesar 2.74 ton ha ${ }^{-1}$, sedangkan pengaruh faktor tunggal dosis pemupukan Ca terbaik adalah pemupukan $\mathrm{Ca} 500 \mathrm{~kg} \mathrm{ha}^{-1}$ sebesar 2.49 ton ha $^{-1}$. Interaksi kedua faktor hanya berbeda nyata meningkatkan tinggi tanaman, bobot kering batang, dan jumlah polong isi.

Kata kunci: biomassa, budidaya jenuh air, kedelai hitam, lahan pasang surut, pemupukan $\mathrm{Ca}$ 


\section{PENDAHULUAN}

Kebutuhan kedelai di Indonesia terus meningkat bersamaan dengan penngkatan jumlah penduduk yang sekarang diperkirakan telah mencapai 269.16 juta jiwa (BPS, 2013). Kekurangan kedelai nasional dipenuhi melalui impor yang dilaporkan mencapai 1.96 juta ton (Pusdatin, 2015). Swasembada kedelai yang ditargetkan pemerintah pada tahun 2018 terancam tidak dapat terwujud. Penelitian Aldillah (2015) menampilkan ramalan bahwa nilai neraca antara produksi dan konsumsi menghasilkan nilai defisit sebesar 1.59 juta ton yang artinya target swasembada kedelai pada tahun 2018 tidak terwujud. Peningkatan produksi kedelai nasional harus dilakuan melalui upaya strategis yang efektif dan efisien.

Kedelai hitam merupakan salah satu komoditas pertanian yang sangat dibutuhkan di Indonesia. Pemanfaatan utama kedelai hitam adalah bahan baku pembuatan kecap meskipun sekarang kedelai hitam mulai dipertimbangkan sebagai bahan baku olahan kedelai seperti tempe dan tahu karena kandungannya yang baik untuk penderita Diabetes Melitus (Zakaria et al., 2016). Irwanto et al. (2016) menyebutkan bahwa kedelai hitam mengandung antosianin, isoflavon, dan saponin. Pemanfaatan kedelai hitam yang semakin luas dan ditambah oleh peningkatan jumlah penduduk Indonesia secara pasti akan menambah besar jumlah kebutuhan kedelai hitam nasional.

Salah satu upaya peningkatan produksi kedelai nasional dilakukan melalui upaya ekstensifikasi pertanian pada upaya pemanfaatan lahan-lahan marjinal termasuk lahan pasang surut. Menurut Nugroho et al. (1993), luas lahan pasang surut Indonesia mencapai 20.11 juta ha dan 9.53 juta ha dari luas tersebut merupakan lahan yang potensial untuk dikembangkan sebagai lahan pertanian. Nazemi et al. (2012) menyatakan bahwa beberapa kendala pengembangan pertanian di lahan pasang surut adalah fluktuasi rejim air atau pola tergenangnya lahan, keragaman kondisi fisika dan kimia tanah, kemasaman tanah yang tinggi, adanya zat bersifat toksik, intuisi air garam, dan rendahnya kesuburan tanah.

Budidaya Jenuh Air (BJA) merupakan paket teknologi budidaya yang telah terbukti dapat menekan sifat negatif dari lahan pasang surut untuk dikembangkan sebagai lahan tanam kedelai. BJA adalah penanaman dengan memberikan irigasi terus menerus dan membuat tinggi muka air tetap sehingga lapisan di bawah perakaran berada dalam kondisi jenuh air (Hunter et al., 1980). Aplikasi BJA di lahan pasang surut terbukti meningkatkan produktivitas kedelai hingga 4.5 ton ha-1 (Pujiwati et al., 2016).

BJA sebagai suatu teknologi budidaya perlu dibentuk menjadi paket teknologi yang berkelanjutan. Salah satu upaya menyempurnakan paket teknologi BJA adalah pemanfaatan biomassa asli pasang surut dan pemupukan $\mathrm{Ca}$. Pemberian biomassa di lahan pasang surut dapat menekan efek negatif $\mathrm{Fe}$, meningkatkan KTK, dan menambah ketersediaan C organik (Khairatun dan Ningsih, 2013). Pola pertanaman sawah pasang surut menghasilkan ketersediaan biomassa jerami dan gulma termasuk golongan teki (Adri et al., 2013; Asikin 2014). Elemen yang tidak kalah pentingnya dalam BJA kedelai di lahan pasang surut adalah pemupukan kalsium karena Ghulamahdi (2017) menyebutkan bahwa kandungan kalsium pada pertanaman kedelai BJA terbilang kurang apabila dibandingkan dengan pertanaman kedelai di lahan kering. Padahal kalsium menurut Hong Bo et al. (2008) berfungsi sebagai penyeimbang kation untuk anion-anion organik dalam vakuola dan sitosol. Kalsium pada sitosol tersebut berperan sebagai koordinator respon berbagai isyarat perkembangan dan kondisi lingkungan. Penelitian ini bertujuan untuk menentukan jenis biomassa dan dosis pemupukan Ca yang mampu meningkatkan pertumbuhan dan produksi kedelai hitam dengan budidaya jenuh air di lahan pasang surut.

\section{BAHAN DAN METODE}

Penelitian dilaksanakan di Desa Karyabhakti, Kecamatan Rantau Rasau, Kabupaten Tanjung Jabung Timur, Provinsi Jambi dari bulan Agustus hingga November 2017. Pengukuran bobot kering dilakukan di Laboratorium Pascapanen Departemen Agronomi dan Hortikultura IPB. Alat yang digunakan adalah peralatan pertanian, meteran, bambu, timbangan analitik, oven, dan kamera untuk dokumentasi. Bahan yang digunakan meliputi benih kedelai hitam varietas Detam 2, Rhizobium sp, kapur tohor $\left(\mathrm{Ca}(\mathrm{OH})_{2}\right)$, dolomit $\left(\mathrm{CaCO}_{3}\right)$, pupuk urea, pupuk SP36, pupuk $\mathrm{KCl}$, pupuk daun gandasil D dan gandasil B, fungisida berbahan aktif karbofuran, herbisida berbahan dasar isopropilamina glifosat dan 2.4-dimetil amina (2.4 D), insektisida berbahan aktif metomil, serta rodentisida berbahan aktif brodifakum.

Percobaan menggunakan rancangan petak tersarang (nested design) dengan dua faktor, yaitu sumber biomassa dan dosis pupuk Ca. Fakor sumber biomassa terdapat tiga taraf, yaitu tanpa biomassa (B0), biomassa teki-tekian (B1), dan biomassa jerami (B2), sedangkan dosis pemupukan $\mathrm{Ca}$ menggunakan kapur tohor 
meliputi empat taraf, yaitu tanpa pupuk Ca (T0), pupuk Ca $250 \mathrm{~kg} \mathrm{ha}^{-1}$ (T1), pupuk Ca $500 \mathrm{~kg} \mathrm{ha}^{-1}$ (T2), dan pupuk Ca $750 \mathrm{~kg} \mathrm{ha}^{-1}$ (T3). Masingmasing kombinasi faktor diulang sebanyak tiga kali sehingga menghasilkan 36 satuan percobaan.

Prosedur penelitian dimulai dengan pemilihan lokasi tanam yang mengandung biomassa teki-tekian dan jerami. Pengolahan tanah dilakukan setelah dilakukan penyemprotan herbisida dengan merebahkan sumber biomassa menggunakan traktor, pembuatan saluran-saluran kecil dengan jarak antarsaluran adalah $3.6 \mathrm{~m}$ dengan lebar $30 \mathrm{~cm}$ dan kedalaman $25 \mathrm{~cm}$ (Gambar 1), serta pengapuran dan pemberian pupuk dasar. Dosis pengapuran adalah sebesar $500 \mathrm{~kg} \mathrm{ha}^{-1}$, sedangkan pemupukan dasar meliputi SP36 (300 kg ha- $\left.{ }^{-1}\right)$ dan KCl (150 kg ha $\left.{ }^{-1}\right)$. Penanaman dilakukan satu minggu setelah pengolahan lahan dengan jarak tanam $40 \times 12.5$ $\mathrm{cm}$. Benih diinokulasikan Rhizobium $\mathrm{sp}$ dan ditanam sebanyak dua benih per lubang tanam. Pemupukan daun urea dilakukan pada pertanaman umur 3 MST sampai dengan 5 MST dengan dosis urea $10 \mathrm{~g} \mathrm{l}^{-1}$ dan volume semprot $400 \mathrm{l} \mathrm{ha}^{-1}$, sedangkan pemupukan gandasil dilakukan pada umur 4 MST (gandasil D) dan 8 MST (gandasil B) dengan dosis $1 \mathrm{~g} \mathrm{l}^{-1}$. Perlakuan kapur tohor diberian pada umur tanaman 3 MST dengan cara diberikan pada alur dekat perakaran. Pemeliharaan meliputi penyiangan gulma dan pengendalian hama. Panen dilakukan setelah $90 \%$ populasi telah luruh daunnya dan polong berwarna kuning kecoklatan, yaitu saat umur 14 MST.

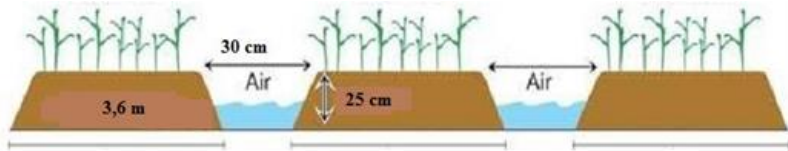

Gambar 1. Penampang saluran budidaya jenuh air

Data didapatkan secara kuantitatif melalui pengamatan pada pertanaman meliputi tinggi tanaman, jumlah daun, waktu $50 \%$ populasi berbunga, jumlah cabang produktif, serta bobot kering akar, batang, daun, dan bintil akar. Pengamatan produksi meliputi jumlah polong isi dan hampa per tanaman contoh, bobot 100 biji, dan bobot biji per ubinan ukuran $3.6 \times 2 \mathrm{~m}$. Data selanjutnya dianalisis dengan uji $F$ dengan aplikasi SAS. Data yang menunjukkan pengaruh nyata selanjutnya diuji dengan Duncan Multiple Range Test (DMRT) pada taraf 5\%.

\section{HASIL DAN PEMBAHASAN}

\section{Kondisi Umum}

Lahan penelitian merupakan lahan pasang surut tipe B, yaitu lahan yang selalu terluapi oleh air pasang saat pasang besar (Widjaja-Adhi et al., 1992). Dampak dari tipe lahan pasang surut menyebabkan kondisi pertanaman selalu dalam keadaan jenuh air. Kedelai pada kondisi jenuh air di awal pertumbuhan akan menampilkan performa pertumbuhan yang kurang baik, tetapi kedelai akan mengalami aklimatisasi dan memperbaiki pertumbuhannya (Ghulamahdi et al., 2009). Aklimatisasi terjadi pada umur 3 MST hingga 5 MST pada pertanaman sehingga dilakukan pemupukan melalui daun karena akar masih dalam masa adaptasi.

Tabel 1 menunjukkan waktu berbunga kedelai hitam varietas Detam 2 berbunga lebih lambat dari waktu seharusnya. Marsetyowati (2014) menyebutkan bahwa mekarnya bunga suatu tanaman membutuhkan energi yang cukup besar sehingga karbohidrat harus berada pada keadaan yang cukup. Karbohidrat sebagai hasil dari fotosintesis terhambat akibat adanya tahap aklimatisasi.

Tabel 1. Rata-rata umur 50\% populasi berbunga kedelai hitam pada tiap petak perlakuan

\begin{tabular}{lcccc}
\hline \multirow{2}{*}{ Sumber Biomassa } & \multicolumn{4}{c}{ Waktu Berbunga (HST) } \\
\cline { 2 - 5 } & \multicolumn{3}{c}{ Dosis Pemupukan Ca $\left(\mathrm{kg} \mathrm{ha}^{-1}\right)$} \\
\cline { 2 - 5 } & Kontrol & 250 & 500 & 750 \\
\hline Tanpa biomassa & 38.33 & 38.67 & 39.00 & 37.67 \\
Teki & 39.33 & 39.00 & 39.67 & 39.00 \\
Jerami & 38.67 & 39.33 & 38.67 & 38.00 \\
\hline
\end{tabular}

Keterlambatan dalam berbunga menyebabkan keterlambatan dalam pengisian polong selain akibat dari pasang yang semakin intensif menyerang pada umur tanaman 7 MST. Genangan akibat pasang menampilkan keterlambatan dalam tahap pengisian polong. Beberapa akibat dari kondisi lingkungan yang tergenang pada penelitian ini adalah banyak bunga yang gugur, polong tidak terisi penuh, waktu panen yang mundur hingga 15 hari, serta penurunan potensi hasil. Hapsari dan Adie (2010) menyebutkan bahwa genangan menyebabkan pertumbuhan terhambat dan penurunan hasil. Penurunan hasil yang terjadi akibat genangan pada fase generatif cenderung lebih besar (50$56 \%$ ) dibandingkan genangan pada fase vegetatif (17-43\%).

Organisme Pengganggu Tanaman yang menyerang pertanaman adalah berupa hama dan gulma. Hama yang menyerang meliputi ulat grayak (Spodoptera litura) dan penggulung daun (Lamprosema indicata) pada umur 4 MST, sedangkan hama yang menyerang di masa generatif adalah kepik hijau. Serangan hama yang sangat tinggi menyebabkan daun bolong dan menggulung sehingga memengaruhi hasil. Pengendalian hama yang dilakukan dengan 
penyemprotan insektisida berbahan aktif metomil pada pagi atau sore hari. Serangan gulma pada pertanaman berupa padi yang mengalami ratun, teki-tekian (Cyperus sp.), rumput purun tikus (Eleocharis dulcis), dan paku-pakuan dari jenis Stenochlaena palustris dikendalikan dengan penyiangan secara manual. Beberapa gulma tersebut hampir sama dengan gulma yang terdapat pada lahan pasang surut Kalimantan Selatan (Asikin, 2014).

\section{Respon Tanaman Hasil Sidik Ragam}

Hasil sidik ragam menunjukkan bahwa pemberian jenis biomassa dan pemupukan $\mathrm{Ca}$ memberikan respon yang berbeda-beda. Pemberian biomassa sangat nyata dalam meningkatkan tinggi tanaman, jumlah daun pada 2 dan 8 MST, jumlah cabang produktif, bobot kering bintil akar, jumlah polong isi, bobot 100 biji, bobot ubinan, serta produktivitas, sedangkan pemupukan $\mathrm{Ca}$ berpengaruh sangat nyata meningkatkan tinggi tanaman dan jumlah daun pada 4 MST sampai dengan 8 MST, bobot kering bintil akar, jumlah polong isi, bobot 100 biji, bobot ubinan, serta produktivitas kedelai hitam varietas Detam 2. Sumber biomassa dan pemberian $\mathrm{Ca}$ sama-sama tidak memberikan pengaruh nyata terhadap variabel pengamatan bobot kering daun dan jumlah polong kosong. Selain bobot kering daun perlakuan jenis biomassa tidak memberikan pengaruh nyata terhadap jumlah daun umur 4 MST, bobot kering total dan bobot kering akar sedangkan pemupukan $\mathrm{Ca}$ tidak berpengaruh nyata terhadap tinggi tanaman dan jumlah daun umur 2 MST, jumlah cabang produktif, serta bobot kering batang. Interaksi kedua perlakuan memberikan pengaruh sangat nyata terhadap tinggi tanaman umur 6 dan 8 MST, serta jumlah polong isi, sedangkan pada variabel pengamatan lain interaksi dua perlakuan tidak memberikan pengaruh nyata kecuali pada variabel bobot kering batang yang menunjukkan pengaruh nyata. Rekapitulasi analisis sidik ragam secara umum dapat dilihat pada Tabel 2.

Rachman et al. (2007) menyebutkan bahwa lahan pasang surut akan sesuai untuk pertumbuhan tanaman apabila diterapkan teknologi terkait konservasi tanah, pengelolaan air, ameliorasi, dan pengelolaan bahan organik, serta pemupukan. Pemberian biomassa dan pengapuran merupakan suatu ameliorasi, yaitu pemberian amelioran sebagai bahan pembenah tanah untuk memperbaiki sifat negatif tanah yang akan berdampak pada pertumbuhan tanaman.

Pemupukan $\mathrm{Ca}$ dengan kapur tohor selain dimaksudkan untuk meningkatkan ketersediaan kalsium yang dapat terserap tanaman, pemupukan
Tabel 2. Rekapitulasi hasil sidik ragam beberapa variabel kuantitatif pengaruh sumber keragaman

\begin{tabular}{|c|c|c|c|c|c|}
\hline \multirow{2}{*}{$\begin{array}{l}\text { Peubah } \\
\text { Pengamatan }\end{array}$} & \multicolumn{5}{|c|}{ Sumber Keragaman } \\
\hline & $\mathrm{B}$ & $\begin{array}{c}\text { Ulangan } \\
\text { (Biomassa) }\end{array}$ & $\mathrm{T}$ & $\mathrm{B} * \mathrm{~T}$ & KK \\
\hline \multicolumn{6}{|l|}{$\begin{array}{l}\text { Tinggi } \\
\text { tanaman }\end{array}$} \\
\hline $2 \mathrm{MST}$ & $* *$ & $\operatorname{tn}$ & tn & $\operatorname{tn}$ & 1.447 \\
\hline $4 \mathrm{MST}$ & $* *$ & $\operatorname{tn}$ & $* *$ & $\operatorname{tn}$ & 4.689 \\
\hline $6 \mathrm{MST}$ & $* *$ & $\operatorname{tn}$ & $* *$ & $* *$ & 3.202 \\
\hline $8 \mathrm{MST}$ & $* *$ & $\operatorname{tn}$ & $* *$ & $* *$ & 3.130 \\
\hline \multicolumn{6}{|l|}{ Jumlah daun } \\
\hline $2 \mathrm{MST}$ & $* *$ & $\operatorname{tn}$ & tn & tn & 5.177 \\
\hline $4 \mathrm{MST}$ & tn & $\operatorname{tn}$ & $* *$ & $\operatorname{tn}$ & 11.270 \\
\hline $6 \mathrm{MST}$ & $*$ & $\operatorname{tn}$ & $* *$ & $\operatorname{tn}$ & 2.760 \\
\hline $8 \mathrm{MST}$ & $* *$ & $\operatorname{tn}$ & $* *$ & $\operatorname{tn}$ & 3.147 \\
\hline $\begin{array}{l}\text { Cabang } \\
\text { produktif }\end{array}$ & $* *$ & $\operatorname{tn}$ & tn & $\operatorname{tn}$ & 18.897 \\
\hline Bobot kering & & & & & \\
\hline Total & tn & $\operatorname{tn}$ & $*$ & $\operatorname{tn}$ & 19.966 \\
\hline Daun & tn & tn & tn & $\operatorname{tn}$ & 27.795 \\
\hline Batang & $*$ & $\operatorname{tn}$ & tn & $*$ & 26.556 \\
\hline Akar & tn & $\operatorname{tn}$ & $*$ & $\operatorname{tn}$ & 21.196 \\
\hline Bintil akar & $* *$ & $\operatorname{tn}$ & $* *$ & tn & 37.630 \\
\hline $\begin{array}{l}\text { Jumlah } \\
\text { polong isi }\end{array}$ & $* *$ & $\operatorname{tn}$ & $* *$ & $* *$ & 6.814 \\
\hline $\begin{array}{l}\text { Jumlah } \\
\text { polong }\end{array}$ & tn & tn & tn & tn & 16.547 \\
\hline kosong & & & & & \\
\hline $\begin{array}{l}\text { Bobot } \\
\text { ubinan }\end{array}$ & $* *$ & $\operatorname{tn}$ & $* *$ & tn & 4.606 \\
\hline $\begin{array}{l}\text { Bobot } 100 \\
\text { biji }\end{array}$ & $* *$ & tn & $* *$ & tn & 4.865 \\
\hline Produktivitas & $* *$ & $\operatorname{tn}$ & $* *$ & tn & 4.575 \\
\hline
\end{tabular}

Keterangan : B=Biomassa; T=Kapur Tohor; * berpengaruh nyata; ** berpengaruh sangat nyata; th tidak berpengaruh nyata

tersebut turut andil dalam upaya ameliorasi. Hal tersebut senada dengan penelitian Noya et al. (2014) yang menyatakan bahwa pemberian kapur pada BJA dapat memberikan pengaruh nyata dalam meningkatkan produktivitas meskipun lahan tersebut sudah mengalami pengapuran sebelumnya.

\section{Pemberian Biomassa terhadap Pertumbuhan dan Produksi Kedelai}

Biomassa teki-tekian (B1) secara umum menunjukkan pengaruh yang cenderung lebih baik terhadap jumlah cabang produktif, tinggi tanaman, dan jumlah daun dibandingkan perlakuan tanpa biomassa (B0) dan biomassa jerami (B2) seperti yang ditunjukkan pada Tabel 3. Tabel 3 menunjukkan biomassa teki memberikan pengaruh yang berbeda nyata dibandingkan kontrol dan biomassa jerami dalam meningkatkan jumlah cabang produktif. Perlakuan B1 memberikan pengaruh yang nyata dalam meningkatkan jumlah 
Tabel 3. Pengaruh sumber biomassa terhadap tinggi tanaman, jumlah daun, dan jumlah cabang produktif kedelai hitam varietas Detam 2

\begin{tabular}{lccc}
\hline \multirow{2}{*}{$\begin{array}{l}\text { Peubah } \\
\text { Pengamatan }\end{array}$} & \multicolumn{3}{c}{ Sumber Biomassa } \\
\cline { 2 - 4 } & Kontrol & $\begin{array}{c}\text { Teki- } \\
\text { Tekian }\end{array}$ & Jerami \\
\hline \multicolumn{1}{c}{----------} & Tinggi Tanaman (cm) ---------- \\
MST & $13.37 \mathrm{c}$ & $14.23 \mathrm{~b}$ & $14.78 \mathrm{a}$ \\
$4 \mathrm{MST}$ & $30.48 \mathrm{~b}$ & $32.78 \mathrm{a}$ & $31.68 \mathrm{ab}$ \\
$6 \mathrm{MST}$ & $37.05 \mathrm{~b}$ & $42.26 \mathrm{a}$ & $41.33 \mathrm{a}$ \\
$8 \mathrm{MST}$ & $41.27 \mathrm{c}$ & $47.65 \mathrm{a}$ & $44.67 \mathrm{~b}$ \\
----------- \\
$2 \mathrm{MST}$ & $2.55 \mathrm{c}$ & $3.00 \mathrm{a}$ & $2.84 \mathrm{~b}$ \\
$4 \mathrm{MST}$ & 9.99 & 10.32 & 9.82 \\
$6 \mathrm{MST}$ & $18.24 \mathrm{c}$ & $19.81 \mathrm{a}$ & $19.29 \mathrm{~b}$ \\
$8 \mathrm{MST}$ & $24.91 \mathrm{c}$ & $29.27 \mathrm{a}$ & $27.77 \mathrm{~b}$ \\
Cabang produktif & $4.13 \mathrm{~b}$ & $5.25 \mathrm{a}$ & $4.22 \mathrm{~b}$ \\
\hline
\end{tabular}

Keterangan : angka yang diikuti oleh huruf yang sama pada baris yang sama tidak berbeda nyata berdasarkan uji DMRT pada taraf 5\%; ${ }^{\text {tn }}$ tidak nyata

daun pada seluruh umur pengamatan dibandingkan perlakuan kontrol (B0) dan jerami (B2), tetapi perlakuan B1 secara umum hanya berbeda nyata pada tinggi tanaman umur 8 MST terhadap perlakuan B2 meskipun tinggi tanaman seluruhnya berbeda nyata terhadap tinggi tanaman perlakuan B0. Artinya biomassa teki-tekian dapat dipastikan memberikan pengaruh yang lebih baik dibandingkan jerami meskipun ada indikasi pengaruh biomassa teki lebih nyata terlihat mulai umur 8 MST. Hal tersebut dapat dilihat dari variabel tinggi tanaman yang mulai menampakkan perbedaan terhadap biomassa jerami, serta variabel jumlah cabang produktif yang dihitung pada umur 8 MST.

Biomassa teki yang baru menampakkan pengaruhnya pada umur 8 MST merupakan indikasi bahwa biomassa teki mulai terurai pada umur tanaman tersebut sehingga diperkirakan biomassa teki memiliki kemampuan terurai yang lebih cepat dibandingkan jerami. Kandungan lignin yang lebih besar dari suatu biomassa dibandingkan selulosanya mengindikasikan kesulitan dekomposisi biomassa tersebut yang lebih besar (Nurida et al., 2007). Biomassa teki diduga lebih cepat terurai dibandingkan biomassa jerami karena kandungan lignin teki yang lebih kecil. Pengaruh biomassa jerami yang lebih buruk terhadap pertumbuhan juga diperkirakan karena kondisi lahan bekas padi yang lebih cepat ditumbuhi padi yang tumbuh kembali. Penutupan lahan oleh pengaruh tumbuhnya padi menghasilkan persaingan pertumbuhan sehingga menekan tanaman untuk tumbuh secara optimal.
Pengaruh dari kondisi lahan bekas kedua biomassa tersebut berada selain pada jumlah cabang produktif, tinggi tanaman, dan jumlah daun memengaruhi pada bobot kering tanaman yang tertera pada Tabel 4. Biomassa teki memberikan bobot kering bintil akar yang lebih baik dibandingkan bobot kering bintil akar pemberian biomassa jerami, meskipun tidak berbeda nyata secara statistik. Bobot kering batang oleh pengaruh biomassa jerami yang lebih baik dibandingkan biomassa teki merupakan akibat dari masih baiknya pengaruh biomassa jerami di umur 7 MST (waktu pengamatan desktruktif bobot kering tanaman kedelai) seperti yang terjadi pada tinggi tanaman di umur 6 MST.

Tabel 4. Pengaruh sumber biomassa terhadap bobot kering total, bobot kering akar, batang, dan daun varietas Detam 2 pada 8 MST

\begin{tabular}{lrcc}
\hline Peubah & \multicolumn{3}{c}{ Sumber Biomassa } \\
\cline { 2 - 4 } Pengamatan & Kontrol & Teki-Tekian & Jerami \\
\hline BK Total $(\mathrm{g})$ & 12.50 & 14.50 & 17.06 \\
BK Akar $(\mathrm{g})$ & 2.46 & 2.85 & 3.65 \\
BK Batang $(\mathrm{g})$ & $4.86 \mathrm{~b}$ & $5.30 \mathrm{~b}$ & $6.64 \mathrm{a}$ \\
BK Daun $(\mathrm{g})$ & 4.78 & 5.40 & 5.99 \\
BK Bintil Akar $(\mathrm{g})$ & $0.38 \mathrm{~b}$ & $0.94 \mathrm{a}$ & $0.78 \mathrm{a}$ \\
\hline
\end{tabular}

Keterangan : angka yang diikuti oleh huruf yang sama pada baris yang sama tidak berbeda nyata berdasarkan uji DMRT pada taraf 5\%; ${ }^{\text {tn }}$ tidak nyata

Pengaruh pemberian biomassa terhadap beberapa komponen hasil kedelai hitam varietas Detam 2 dapat dilihat pada Tabel 5. Munculnya bunga yang terjadi pada umur sekitar 5 MST sehingga mengindikasikan bahwa masa generatif atau masa produktif kedelai dimulai saat itu. Biomassa teki secara umum berbeda nyata dalam meningkatkan seluruh komponen hasil pada Tabel 5 kecuali pada variabel jumlah polong kosong.

Tabel 5. Respon tanaman pada beberapa komponen hasil oleh pengaruh jenis biomassa

\begin{tabular}{lrcc}
\hline \multirow{2}{*}{$\begin{array}{l}\text { Peubah } \\
\text { Pengamatan }\end{array}$} & \multicolumn{3}{c}{ Sumber Biomassa } \\
\cline { 2 - 4 } & Kontrol & $\begin{array}{c}\text { Teki- } \\
\text { Tekian }\end{array}$ & Jerami \\
\hline Jumlah polong isi & $31.50 \mathrm{c}$ & $38.88 \mathrm{a}$ & $34.30 \mathrm{~b}$ \\
Jumlah polong & 7.96 & 7.65 & 7.30 \\
kosong & & & \\
Bobot ubinan (kg) & $1.51 \mathrm{~b}$ & $1.97 \mathrm{a}$ & $1.56 \mathrm{~b}$ \\
Bobot 100 biji (g) & $12.20 \mathrm{c}$ & $13.98 \mathrm{a}$ & $12.92 \mathrm{~b}$ \\
$\begin{array}{l}\text { Produktivitas (ton } \\
\text { ha }{ }^{-1} \text { ) }\end{array}$ & $2.09 \mathrm{~b}$ & $2.74 \mathrm{a}$ & $2.17 \mathrm{~b}$ \\
\hline
\end{tabular}

Keterangan : angka yang diikuti oleh huruf yang sama pada baris yang sama tidak berbeda nyata berdasarkan uji DMRT pada taraf 5\%; tn tidak nyata 
Pemberian biomassa sebagai pupuk organik pada lahan pasang surut erat kaitannya dalam rangka memperbaiki sifat negatif lahan pasang surut. Pupuk organik dapat mengurangi pengaruh keracunan ion $\mathrm{Fe}$ dengan mengkelatnya. meningkatkan Kapasitas Tukar Kation (KTK) tanah. menambah ketersediaan C-organik. serta meneguhkan stabilitas agregat tanah pada lahan pasang surut (Khairatun dan Ningsih. 2013). Tabel 5 menunjukkan bahwa produktivitas terbaik kedelai hitam varietas Detam 2 adalah 2.74 ton ha${ }^{1}$. yaitu pengaruh dari pemberian biomassa teki.

\section{Dosis Pemupukan Ca terhadap Pertumbuhan dan Produksi Kedelai}

Pemupukan kalsium merupakan suatu usaha dalam menambah ketersediaan kalsium bagi tanaman yang dilakukan pada 3 MST. Aplikasi pupuk Ca pada 3 MST yang tidak bersamaan dengan peupukan dasar seperti $\mathrm{P}$ dan $\mathrm{K}$ bertujuan untuk meningkatkan efekivitas penyerapan kalsium karena Nyoki dan Ndakidemi (2018) menyatakan bahwa serapan kalsium berkurang oleh pemupukan $\mathrm{P}$ dan $\mathrm{K}$. Hal tersebut yang menyebabkan pengaruh pemupukan kalsium cenderung tidak nyata pada pengamatan pertumbuhan tanaman umur 2 MST yang tertera pada Tabel 6 .

Pemberian dosis pemupukan kalsium 500 $\mathrm{kg} \mathrm{ha}^{-1}$ dan $750 \mathrm{~kg} \mathrm{ha}^{-1}$ secara umum tidak berbeda nyata pada tinggi tanaman dan cenderung tidak memberikan perbedaan yang signifikan terhadap jumlah daun sehingga pemberian pupuk baik dosis $500 \mathrm{~kg} \mathrm{ha}^{-1}$ maupun $750 \mathrm{~kg} \mathrm{ha}^{-1}$ akan memberikan respon yang relatif sama pada tinggi tanaman dan jumlah daun. Hal yang senada terjadi pada pengamatan destruktif terhadap bobot kering yang dapat dilihat pada Tabel 7. Pemupukan kalsium dengan dengan dosis $500 \mathrm{~kg} \mathrm{ha}^{-1}$ secara umum memang memberikan hasil bobot kering total. bobot kering akar. serta bobot kering bintil akar yang lebih besar dibandingan dosis-dosis lainnya. tetapi hasil tersebut tidak berbeda nyata dengan pemupukan kalsium dosis $750 \quad \mathrm{~kg} \quad \mathrm{ha}^{-1}$ berdasarkan uji DMRT.

Pengaruh pemberian kapur sebagai sumber $\mathrm{Ca}$ dapat meningkatkan beberapa variabel pertumbuhan. Pujiwati et al. (2015) menyebutkan bahwa peningkatan pemberian dosis kapur nyata meningkatkan bobot bintil akar hingga 5.52 gram pada kedelai hitam. Tinggi tanaman. jumlah daun. dan jumlah cabang terbaik juga didapat pada dosis kapur yang cenderung tinggi meskipun tidak nyata secara statistik. Bobot kering bintil akar pada penelitian ini yang lebih rendah dibandingkan dengan penelitian Pujiwai et al. (2015) adalah dampak dari kondisi pertanaman yang lebih sering tergenangi pasang. Taufiq dan Sundari (2015) menyebutkan bahwa salah satu faktor penghambat dalam pembentukan bintil adalah kondisi tergenang. Kondisi tergenang berbeda dengan kondisi jenuh air yang justru meningkatkan pembentukan bintil akar. Adapun di lahan penelitian ini kondisi tergenang lebih sering terjadi dibandingkan kondisi jenuh air sehingga bintil akar banyak yang membusuk.

Tabel 6. Pengaruh dosis pupuk Ca terhadap tinggi tanaman. jumlah daun. dan jumlah cabang produktif kedelai hitam varietas Detam 2

\begin{tabular}{|c|c|c|c|c|}
\hline \multirow{2}{*}{$\begin{array}{l}\text { Peubah } \\
\text { Pengamatan }\end{array}$} & \multicolumn{4}{|c|}{ Dosis Pemupukan $\mathrm{Ca}\left(\mathrm{kg} \mathrm{ha}^{-1}\right)$} \\
\hline & Kontrol & 250 & 500 & 750 \\
\hline & \multicolumn{4}{|c|}{ Tinggi Tanaman $(\mathrm{cm})$----- } \\
\hline $2 \mathrm{MST}$ & & & 14.10 & 14.15 \\
\hline $4 \mathrm{MST}$ & $27.05 \mathrm{c}$ & $30.96 \mathrm{~b}$ & $33.75 \mathrm{a}$ & $34.83 \mathrm{a}$ \\
\hline $6 \mathrm{MST}$ & $35.94 \mathrm{c}$ & $38.01 \mathrm{~b}$ & $43.32 \mathrm{a}$ & $43.58 \mathrm{a}$ \\
\hline $8 \mathrm{MST}$ & $39.91 \mathrm{c}$ & $42.38 \mathrm{~b}$ & $47.64 \mathrm{a}$ & $48.19 \mathrm{a}$ \\
\hline & \multicolumn{4}{|c|}{ Jumlah Daun -. } \\
\hline $2 \mathrm{MST}$ & 2.83 & 2.84 & 2.81 & 2.71 \\
\hline $4 \mathrm{MST}$ & $8.55 \mathrm{~b}$ & $9.96 \mathrm{a}$ & $10.64 \mathrm{a}$ & $11.02 \mathrm{a}$ \\
\hline $6 \mathrm{MST}$ & $17.96 \mathrm{c}$ & $19.11 \mathrm{~b}$ & $19.62 \mathrm{ab}$ & $19.76 \mathrm{a}$ \\
\hline $8 \mathrm{MST}$ & $26.27 \mathrm{c}$ & $27.61 \mathrm{ab}$ & $28.17 \mathrm{a}$ & $27.22 \mathrm{~b}$ \\
\hline $\begin{array}{l}\text { Cabang } \\
\text { nroduktif }\end{array}$ & 4.24 & 4.18 & 5.07 & 4.63 \\
\hline
\end{tabular}

Keterangan : angka yang diikuti oleh huruf yang sama pada baris yang sama tidak berbeda nyata berdasarkan uji DMRT pada taraf 5\%; ${ }^{\text {tn }}$ tidak nyata

Tabel 7. Pengaruh dosis pupuk Ca terhadap bobot kering total. akar. batang. dan bintil akar

\begin{tabular}{lllll}
\hline Peubah & \multicolumn{4}{c}{ Dosis Pemupukan Ca $\left(\mathrm{kg} \mathrm{ha}^{-1}\right)$} \\
\cline { 2 - 5 } Pengamatan & Kontrol & \multicolumn{1}{c}{250} & \multicolumn{1}{c}{500} & \multicolumn{1}{c}{750} \\
\hline BK Total $(\mathrm{g})$ & $13.47 \mathrm{~b}$ & $13.27 \mathrm{~b}$ & $16.94 \mathrm{a}$ & $15.07 \mathrm{ab}$ \\
BK Akar $(\mathrm{g})$ & $2.35 \mathrm{~b}$ & $2.86 \mathrm{ab}$ & $3.55 \mathrm{a}$ & $3.17 \mathrm{ab}$ \\
BK Batang $(\mathrm{g})$ & 5.47 & 5.16 & 6.23 & 5.54 \\
BK Daun $(\mathrm{g})$ & 5.30 & 4.75 & 6.12 & 5.40 \\
BK Bintil Akar $(\mathrm{g})$ & $0.33 \mathrm{~b}$ & $0.49 \mathrm{~b}$ & $1.03 \mathrm{a}$ & $0.95 \mathrm{a}$ \\
\hline
\end{tabular}

Keterangan : angka yang diikuti oleh huruf yang sama pada baris yang sama tidak berbeda nyata berdasarkan uji DMRT pada taraf $5 \%$; tn tidak nyata

Respon pemupukan kalsium terhadap komponen hasil kedelai hitam vareitas Detam 2 ditampilkan pada tabel 8. Pemupukan kalsium dosis $500 \mathrm{~kg} \mathrm{ha}^{-1}$ secara keseluruhan memberikan pengaruh yang paling baik. Dosis pupuk kalsium $500 \mathrm{~kg} \mathrm{ha}^{-1}$ berbeda nyata meningkatkan bobot ubinan. bobot 100 biji. dan produktivitas dibandingkan perlakuan lainnya. sedangkan variabel jumlah polong terisi dosis $500 \mathrm{~kg} \mathrm{ha}^{-1}$ hanya berbeda nyata terhadap perlakuan T0 dan T1. Produktivitas tertinggi oleh pengaruh dosis pupuk Ca berada pada dosis pupuk Ca $500 \mathrm{~kg} \mathrm{ha}^{-}$ 
${ }^{1}$ mencapai 2.49 ton $\mathrm{ha}^{-1}$. Penambahan pupuk Ca di atas dosis $500 \mathrm{~kg} \mathrm{ha}^{-1}$ justru menurunkan hasil kedelai hitam. Hal ini bertolak belakang dengan penelitian Toyip (2012) yang menyebutkan bahwa pemupukan $\mathrm{Ca} 1$ ton $\mathrm{ha}^{-1}$ memberikan hasil ubinan paling tinggi. Indikasi yang menjadi perbedaan tersebut adalah tergerusnya pupuk $\mathrm{Ca}$ berupa kapur oleh arus pasang yang besar. Pemupukan $\mathrm{Ca}$ selain memberikan tambahan ketersediaan kalsium pada pertanaman juga berfungsi sebagai amelioran kapur. Ghulamahdi (2017) menjelaskan bahwa unsur penting dari kapur yang berperan menetralkan kemasaman tanah salah satunya adalah $\mathrm{OH}^{-}$. Ion $\mathrm{OH}^{-}$ berikatan pada $\mathrm{Al}^{3+}$ yang pada mulanya terikat pada koloid tanah sehingga seiring dengan ikatan $\mathrm{Al}(\mathrm{OH})_{3}$ yang terbentuk terjadi substitusi pengisian koloid tanah dari $\mathrm{Al}$ menjadi $\mathrm{Ca}$.

Tabel 8. Pengaruh dosis pupuk Ca terhadap beberapa komponen hasil kedelai hitam

\begin{tabular}{lllll}
\hline Peubah & \multicolumn{4}{c}{ Dosis Pemupukan Ca $\left(\mathrm{kg} \mathrm{ha}^{-1}\right)$} \\
\cline { 2 - 5 } Pengamatan & Kontrol & \multicolumn{1}{c}{250} & 500 & 750 \\
\hline Jumlah polong isi & $31.42 \mathrm{~b}$ & $32.16 \mathrm{~b}$ & $38.35 \mathrm{a}$ & $37.65 \mathrm{a}$ \\
Jumlah polong & 7.72 & 7.45 & 7.25 & 8.14 \\
kosong & & & & \\
$\begin{array}{l}\text { Bobot ubinan (kg) } \\
\text { Bobot 100 biji (g) }\end{array}$ & $1.62 \mathrm{~b}$ & $1.65 \mathrm{~b}$ & $1.79 \mathrm{a}$ & $1.65 \mathrm{~b}$ \\
$\begin{array}{l}\text { Produktivitas (ton } \\
\text { ha-1) }\end{array}$ & $2.25 \mathrm{~b}$ & $12.80 \mathrm{~b}$ & $13.96 \mathrm{a}$ & $12.80 \mathrm{~b}$ \\
\hline
\end{tabular}

Keterangan : angka yang diikuti oleh huruf yang sama pada baris yang sama tidak berbeda nyata berdasarkan uji DMRT pada taraf $5 \%$; tn tidak nyata

\section{Pengaruh Interaksi Sumber Biomassa dan} Dosis Pupuk Ca pada Pertumbuhan dan Hasil

Interaksi antara sumber biomassa dan dosis pemupukan $\mathrm{Ca}$ memberikan pengaruh nyata dalam meningkatkan komponen pertumbuhan hanya pada tinggi tanaman umur 6 dan 8 MST dan bobot kering batang seperti yang dapat dilihat pada Tabel 9. Kombinasi terbaik dalam meningkatkan tinggi kedelai di lahan pasang surut adalah penggunaan biomassa jerami dengan dosis pemupukan $\mathrm{Ca}$ sebesar $750 \mathrm{~kg} \mathrm{ha}^{-1}$. meskipun hasil uji DMRT pengaruh tersebut tidak berbeda nyata atau sama saja dengan kombinasi biomassa teki dengan pemupukan $\mathrm{Ca} 500 \mathrm{~kg} \mathrm{ha}^{-1}$ dan 750 $\mathrm{kg} \mathrm{ha}^{-1}$. serta biomassa jerami dengan pemupukan Ca $500 \mathrm{~kg} \mathrm{ha}^{-1}$. Bobot kering batang terbaik didapat pada pemberian biomassa jerami dan pemupukan Ca $500 \mathrm{~kg} \mathrm{ha}^{-1}$.

Pengaruh interaksi biomassa jerami dan kapur cenderung menampakkan pertumbuhan yang lebih baik dibandingkan biomassa tekitekian. Penelitian Nugroho (2013) menyimpulkan bahwa perpaduan pemberian kapur dan mulsa jerami memberikan respon pertumbuhan paling baik. Yulia dan William (2006) menjelaskan bahwa penggunaan mulsa jerami berpengaruh terhadap penurunan kemasaman tanah ( $\mathrm{pH}$ tanah). kadar zat arang atau $\mathrm{C}$ organik tanah. dan $\mathrm{C} / \mathrm{N}$ rasio. tetapi meningkatkan kandungan nitrogen total dan serapan hara P. Interaksi yang lebih baik antara biomassa jerami dan pemupukan $\mathrm{Ca}$ dengan kapur karena adanya kesamaan efek dari kedua faktor tersebut untuk memperbaki kondisi tanah sehingga tanaman dapat tumbuh lebih baik.

Interaksi sumber biomassa dan dosis pemupukan $\mathrm{Ca}$ hanya memberikan pengaruh nyata dalam meningkatkan komponen hasil pada variabel jumlah polong isi seperti yang tertera pada tabel 10. Kombinasi perlakuan terbaik dalam meningkatkan jumlah polong isi adalah pemberian biomassa teki dengan pemupukan Ca $500 \mathrm{~kg} \mathrm{ha}^{-1}$ (B1T2) dan biomassa teki dengan pemupukan $\mathrm{Ca}$ $750 \mathrm{~kg} \mathrm{ha}^{-1}$. Produktivitas tertinggi kedelai di lahan pasang surut akan didapat pada kombinasi pemberian biomassa teki dengan pemupukan $\mathrm{Ca}$ dosis $500 \mathrm{~kg} \mathrm{ha}^{-1}$. yaitu sebesar 2893 ton $\mathrm{ha}^{-1}$ meskipun hasil tersebut tidak berbeda nyata.

Tabel 9. Pengaruh dosis pupuk Ca terhadap beberapa komponen hasil kedelai hitam

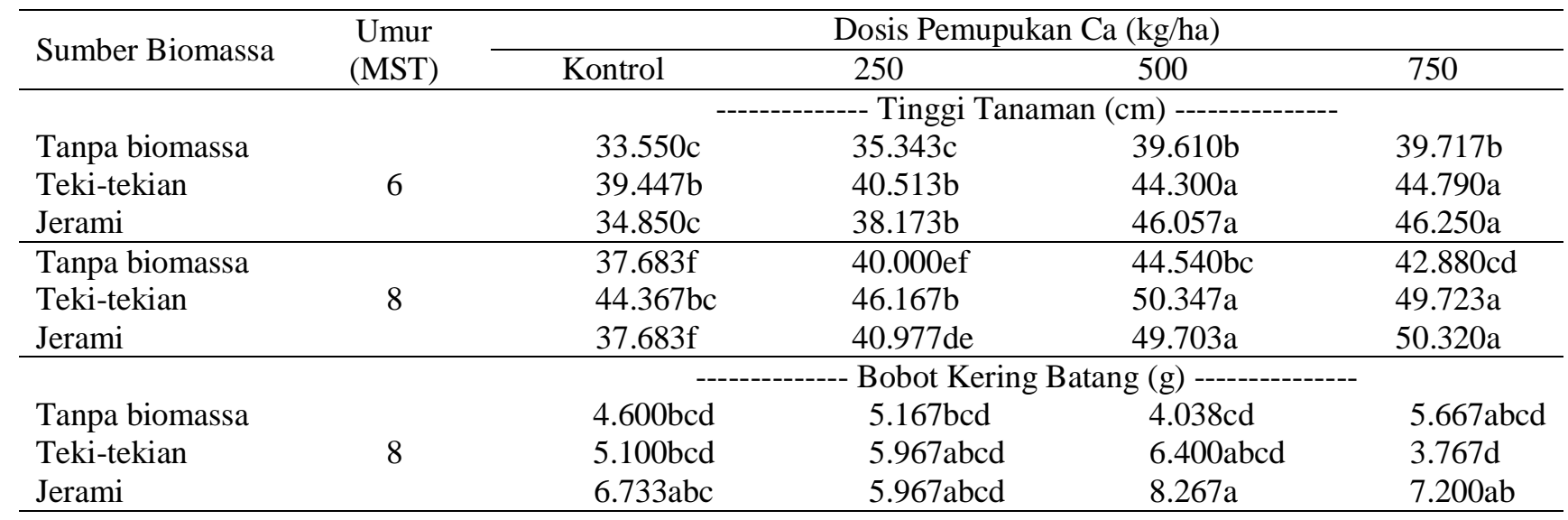

Keterangan : angka yang diikuti oleh huruf yang sama pada baris yang sama tidak berbeda nyata berdasarkan uji DMRT pada taraf 5\%; tn tidak nyata 
Tabel 10. Pengaruh interaksi biomassa dan dosis pupuk $\mathrm{Ca}$ terhadap komponen hasil

\begin{tabular}{|c|c|c|c|c|}
\hline \multirow{2}{*}{$\begin{array}{l}\text { Sumber } \\
\text { Biomassa }\end{array}$} & \multicolumn{4}{|c|}{ Dosis Pemupukan $\mathrm{Ca}\left(\mathrm{kg} \mathrm{ha}^{-1}\right)$} \\
\hline & Kontrol & 250 & 500 & 750 \\
\hline & \multicolumn{4}{|c|}{----------- Jumlah Polong Isi ----------- } \\
\hline $\begin{array}{l}\text { Tanpa } \\
\text { biomassa }\end{array}$ & $30.667 d$ & $30.167 d$ & $33.867 \mathrm{bcd}$ & $31.333 \mathrm{~d}$ \\
\hline $\begin{array}{l}\text { Teki- } \\
\text { tekian }\end{array}$ & $32.200 \mathrm{~cd}$ & $33.767 \mathrm{bcd}$ & $45.067 \mathrm{a}$ & $44.500 \mathrm{a}$ \\
\hline \multirow[t]{2}{*}{ Jerami } & $31.400 \mathrm{~d}$ & $32.567 \mathrm{~cd}$ & $36.133 b c$ & $37.133 b$ \\
\hline & \multicolumn{4}{|c|}{--------- Produktivitas $\left(\right.$ ton $\mathrm{ha}^{-1}$ ) --------- } \\
\hline $\begin{array}{l}\text { Tanpa } \\
\text { biomassa }\end{array}$ & 2.026 & 2.016 & 2.273 & 2.076 \\
\hline $\begin{array}{l}\text { Teki- } \\
\text { tekian }\end{array}$ & 2.593 & 2.706 & 2.893 & 2.770 \\
\hline Jerami & 2.150 & 2.183 & 2.316 & 2.066 \\
\hline
\end{tabular}

Keterangan : angka yang diikuti oleh huruf yang sama pada baris yang sama tidak berbeda nyata berdasarkan uji DMRT pada taraf 5\%; ${ }^{\text {tn }}$ tidak nyata

\section{KESIMPULAN}

Pemberian biomassa dan pemupukan $\mathrm{Ca}$ memberikan pengaruh yang berbeda pada pertumbuhan dan produksi kedelai hitam dengan budidaya jenuh air di lahan pasang surut. tetapi perlakuan keduanya secara umum memberikan pengaruh yang nyata dalam meningkatkan pertumbuhan dan produksi. Pemberian biomassa dan pemupukan $\mathrm{Ca}$ secara umum sangat nyata dalam meningkatkan tinggi tanaman. jumlah daun. bobot kering bintil akar. jumlah polong isi. bobot ubinan. bobot 100 biji. dan produktivitas. Perlakuan biomassa teki memberikan pengaruh paling baik dalam meningkatkan produktivitas.yaitu sebesar 2.74 ton $\mathrm{ha}^{-1}$. sedangkan dosis pupuk Ca $500 \mathrm{~kg} \mathrm{ha}^{-1}$ merupakan dosis pemupkan $\mathrm{Ca}$ yang menghasilkan produktivitas terbaik sebesar 2.49 ton ha ${ }^{-1}$. Interaksi kedua faktor nyata dalam meningkatkan tinggi tanaman umur 6 dan 8 MST. bobot kering batang. dan jumlah polong isi.

\section{DAFTAR PUSTAKA}

Adri, Firdaus, Suharyon, Yardha. 2013. Potensi dan peluang peningkatan indeks pertanaman lahan rawa pasang surut di kabupaten tanjung jabung timur. Jurnal Ilmiah Sosio-Ekonomika Bisnis. 16 (1): 100- 108.

Aldillah, R. 2015. Proyeksi produksi dan konsumsi kedelai indonesia. JEKT. 8 (1): 923.

Asikin, S. 2014. Serangga dan serangga musuh alami yang berasosiasi pada tumbuhan liar dominan di lahan pasang surut. Prosiding
Seminar Nasional Inovasi Teknologi Pertanian Spesifik Lokasi di Banjarbaru. 67 Agustus 2014.

[BPS] Badan Pusat Statistik. 2013. Proyeksi Penduduk Indonesia 2010-2035. BPS. Jakarta.

Ghulamahdi, M. 2017. Adaptasi Kedelai Budidaya Jenuh Air untuk Produktivitas Tinggi di Lahan Pasang Surut. IPB Press. Bogor.

Ghulamahdi, M., M. Melati, D. Sagala. 2009. Production of soybean under saturated soil culture on tidal swamps. Jurnal Agronomi Indonesia. 37 (3): 226-232.

Hapsari, R.T., M.M. Adie. 2010. Peluang perakitan dan pengembangan kedelai toleran genangan. Jurnal Litbang Pertanian. 29 (2): 50-57.

Hong-Bo, S., S. Wei-Yi, C. Li-Ye. 2008. Advances of calcium signals involved in plant anti-drought. C.R. Biologies. 331: 587-596.

Hunter, M.N., P.L.M. De Fabrun, D.E. Byth. 1980. Response of nine soybean line to soil moisture conditions close to saturation. Aust J Exp Agric Anim Husb. 2: 68-75.

Irwanto, R., D.R. Adawiyah, F.R. Zakaria. Peran fisiologis sari kedelai hitam diperkaya mikroenkapsulan minyak sawit mentah pada penderita diabetes melitus tipe 2 . J. Teknol. dan Industri Pangan. 27 (1): 1- 9.

Khairatun, N., R.D. Ningsih. 2013. Penggunaan pupuk organik untuk mengurangi pupuk anorganik dan peningkatan produktivitas padi di lahan pasang surut. Dalam M. Yasin, A. Noor, Suryana, A. Hasbianto, N. Amali, Y. Pribadi (eds.). Seminar Nasional Inovasi Teknologi Pertanian. Banjarbaru, 26-27 Maret 2013.

Marsetyowati, T. 2014. Teknik Pengemasan dalam transportasi untuk mempertahankan mutu bunga potong alpina (Alpinia purpurata). Widyariset. 17 (2): 205-212.

Nazemi, D., A. Hairani, Nurita. 2012. Optimalisasi pemanfaatan lahan rawa pasang surut melalui pengelolaan lahan dan komoditas. Agrovigor. 5 (1): 52-57.

Noya, A.I., M. Ghulamahdi, D. Sopandie, A. Sutandi, M. Melati. 2014. Pengaruh kedalaman muka air dan amelioran terhadap produktivitas kedelai di lahan sulfat masam. Pangan. 23 (2): 120-133. 
Nugroho, A.S. 2013. Pengaruh varietas dan kombinasi pupuk terhadap pertumbuhan dan produktivitas kedelai pada budidaya jenuh air di lahan pasang surut. [Skripsi]. Institut Pertanian Bogor. Bogor.

Nugroho, K., Alkusuma, Paidi, W. Wahdini, Abdurachman, H. Sutardjo I.P.G. WidjajaAdhi. 1993. Peta Areal Potensial untuk Pengembangan Pertanian Lahan Rawa Pasang Surut. Rawa. dan Pantai. Pusat Penelitian Tanah dan Agroklimat Balitbangtan. Bogor.

Nurida, N.L., O. Haridjaja, S. Arsyad, Sudarsono, U. Kurnia, G. Djajakirana. 2007. Perubahan fraksi bahan organik tanah akibat perbedaan cara pemberian dan sumber bahan organik pada ultisols jasinga. Jurnal Tanah dan Iklim. 26: 29-40.

Nyoki, D., P.A. Ndakidemi. 2018. Rhizobium inoculation reduces $\mathrm{P}$ and $\mathrm{K}$ fertilization requirement in corn-soybean intercropping. Rhizospere. 5: 51-56.

Pujiwati, H., M. Ghulamahdi, S. Yahya, S.A. Aziz, O. Haridjaja. 2015. Efisiensi pengapuran dengan amelioran air gambut memperbaiki adaptasi kedelai hitam (Glycine soja) terhadap cekaman $\mathrm{Al}$ dan $\mathrm{Fe}$ di lahan pasang surut. Dalam S. Herlinda, Suwandi, Tanbiyaskur, D. Nursyamsi, M. Noor, S. Anwar (eds.). Prosiding Seminar Nasional Lahan Suboptimal 2015. Palembang, 8-9 Oktober 2015.

Pujiwati, H., M. Ghulamahdi, S. Yahya, S.A. Aziz, O. Haridjaja. 2016. Produktivitas tiga genotipe kedelai dengan air berbeda dan kedalaman muka air pada berbagai kondisi tanah di pasang surut. Jurnal Agronomi Indonesia. 44 (3): 248-254.
[Pusdatin] Pusat Data dan Sistem Informasi Pertanian. 2015. Outlook Komoditas Pertanian Tanaman Pangan Kedelai. Pusat Data dan Sistem Informasi Pertanian Kementerian Pertanian. Jakarta.

Rachman, A., I.G.M. Subiksa, Wahyunto. 2007. Perluasan areal tanaman kedelai ke lahan suboptimal. Dalam Sumarno, Suyamto, A. Widjono, Hermanto, H. Kasim (eds.). Kedelai, Teknik Produksi dan Pengembangan. Pusat Penelitian dan Pengembangan Tanaman Pangan. Bogor.

Taufiq, A., T. Sundari. 2012. Respon tanaman kedelai terhadap lingkungan tumbuh. Buletin Palawija. 23: 13-26.

Toyip. 2012. Pengaruh Pemupukan Fosfor dan Kalsium terhadap serapan hara dan produktivitas dua genotipe kedelai pada budidaya jenuh air. J. Agroland. 20 (1): 2836.

Widjaja-Adhi, I.P.G., K. Nugroho, S.D. Ardi, A.S. Karama. 1992. Sumber daya lahan pasang surut. rawa. dan pantai: potensi. keterbatasan. dan pemanfaatan. Dalam S. Parohardjono, M. Syam. (eds.). Risalah Pertemuan Nasional Pengembangan Pertanian Lahan Pasang Surut dan Rawa. Pusat Penelitian dan Pengembangan Tanaman Pangan. Bogor, 3-4 Maret 1992.

Yulia, R., E. William. 2006. Pemberian mulsa terhadap tujuh varietas kacang hijau dan keharaan tanah di lahan lebak tengahan. Buletin Agronomi. 34 (3): 48-152.

Zakaria, F.R., D.P.R. Firdaus, N.D. Yuliana. 2016. Konsumsi tahu kedelai hitam untuk memperbaiki nilai sgot/sgtp dan aktivitas antioksidan plasma penderita diabetes tipe 2. Pangan. 25 (2): 95-104. 